\title{
Uncoupling in Bacterial Growth: ATP Pool Variation in Zymomonas mobilis Cells in Relation to Different Uncoupling Conditions of Growth
}

\author{
By A. LAZDUNSKI AND J. P. BELAICH \\ Laboratoire de Chimie Bactérienne, C.N.R.S., \\ 3I, Ch.J. Aiguier, 13-Marseille, France \\ (Accepted for publication 8 October 1971)
}

\begin{abstract}
SUMMARY
The ATP pool, chosen as a suitable criterion of the cellular energetic state, has been measured in Zymomonas mobilis in different physiological conditions. ATP accumulates when growth is limited by pantothenic acid or blocked by chloramphenicol. A constitutive ATPase activity with a low affinity for ATP has been found which could be responsible for the dissipation of the excess energy produced in uncoupling conditions of growth.
\end{abstract}

\section{INTRODUCTION}

The cellular adenine nucleotide pool may play a central part in the control of energetic metabolism and many scientists have been interested in the determination of this in order to study the inter-relations between the energy-yielding and the energy-consuming processes. Thus, for estimating the cellular energy state, Atkinson \& Fall (1967), Atkinson \& Walton (1967) and Atkinson (1968) proposed the use of the energy charge of the adenylate system (ATP + ADP + AMP) as a parameter, defined as the average number of anhydridebound phosphate groups per adenine moeity. Numerous authors have more simply reported measurements of the intracellular level of ATP with several micro-organisms growing in different conditions of culture-Escherichia coli (Franzen \& Binkley, I96I; Damoglou \& Dawes, 1967; Cole, Wimpenny \& Hughes, 1967), Aerobacter aerogenes (Strange, Wade \& Dark, 1963), Streptococcus faecalis (Forrest, 1965; Forrest \& Walker, 1965), Thiobacillus (Kelly \& Syrett, 1966), and yeast (Polakis \& Bartley, I966). It seems to us that the ATP pool is a suitable parameter for describing the energetic cellular state, as demonstrated by the experiments of Cousin \& Belaich (I966) on the thermosensitive mutants of $E$. coli $\mathrm{K}$ I2 blocked in the adenylate kinase system. We have chosen this parameter in order to follow the energetic cellular state of Zymomonas mobilis growing under different physiological conditions. Indeed, as reported previously (Belaich, Belaich \& Simonpietri, 1972), the growth of this organism can be simply uncoupled by pantothenate starvation. Also, the effect of nitrogen starvation on the cellular rate of catabolic activities has been reported (Belaich \& Senez, 1965a). Thus, this is an ideal system to study the impact of uncoupling on the energetic cellular state of a bacterium.

\section{METHODS}

Strain and media. The strain of Zymomonas mobilis, the media utilized and the culture conditions were the same as those previously described (Belaich et al. 1972). 


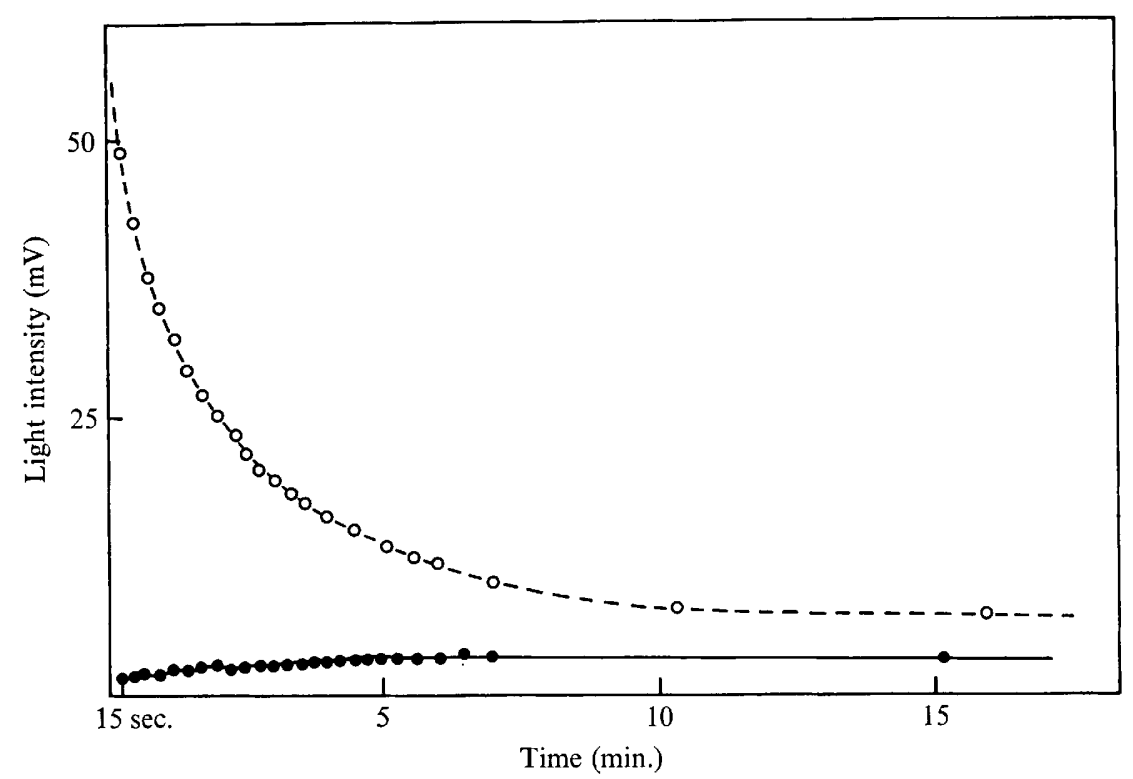

Fig. I. Time dependence of the light production by luciferin-luciferase system O-O, With ATP $(0.8 \mu \mathrm{g} / \mathrm{ml}) ; \bigcirc$, with ADP (I $\mu \mathrm{g} / \mathrm{ml})$.

Chemicals. ATP and ADP were obtained from Schwarz Bioresearch, Inc., and dried firefly lanterns from Sigma Chemical Co., St Louis, Missouri, U.S.A.

Analytical methods. The growth kinetics were obtained with a Bonet-Maury automatic biophotometer. The turbidity was recorded versus time with a device which permits the circulation of the culture from a two-litre culture vessel into the optical cuvets by means of a peristaltic pump.

The growth thermogram was obtained by the technique described by Belaich \& Senez $(1965 b)$.

The light intensity produced by the luciferine-luciferase system was detected in a Dario I 50 UVP photomultiplier tube and recorded with a Sefram potentiometer (Servotrace). The photomultiplier was connected to a THT-SAEME type APM 352 power supply.

Optical densities and dry weight cellular concentration were measured in the manner previously described (Belaich et al. 1972).

ATP was determined by the luciferin-luciferase method first described by Strehler \& Totter (1952). For this purpose, I to Io mg (dry wt) of organism were pipetted into a centrifuge tube containing about $20 \mathrm{mg}$ of crushed ice in order to cool from 30 to $4^{\circ}$ within a minute. From that point, the method of Forrest \& Walker (1965) was followed. Figure I shows the light production versus time in two experiments where approximately the same quantities of ATP and ADP were pipetted into the photomultiplier cell. The light produced at $15 \mathrm{~s}$ is 30 -fold higher for ATP than for ADP. Figure 2 shows the light production (at I5 s) versus ATP concentrations when pure ATP and when a mixture of ATP and ADP were pipetted into the photomultiplier cell. These control experiments demonstrate that ADP did not interfere noticeably in the ATP determinations.

The ATPase was determined by the method reported by Kielley (1955). The liberated phosphorus was measured by the technique of Fiske \& Subbarow (I925), and the proteins 


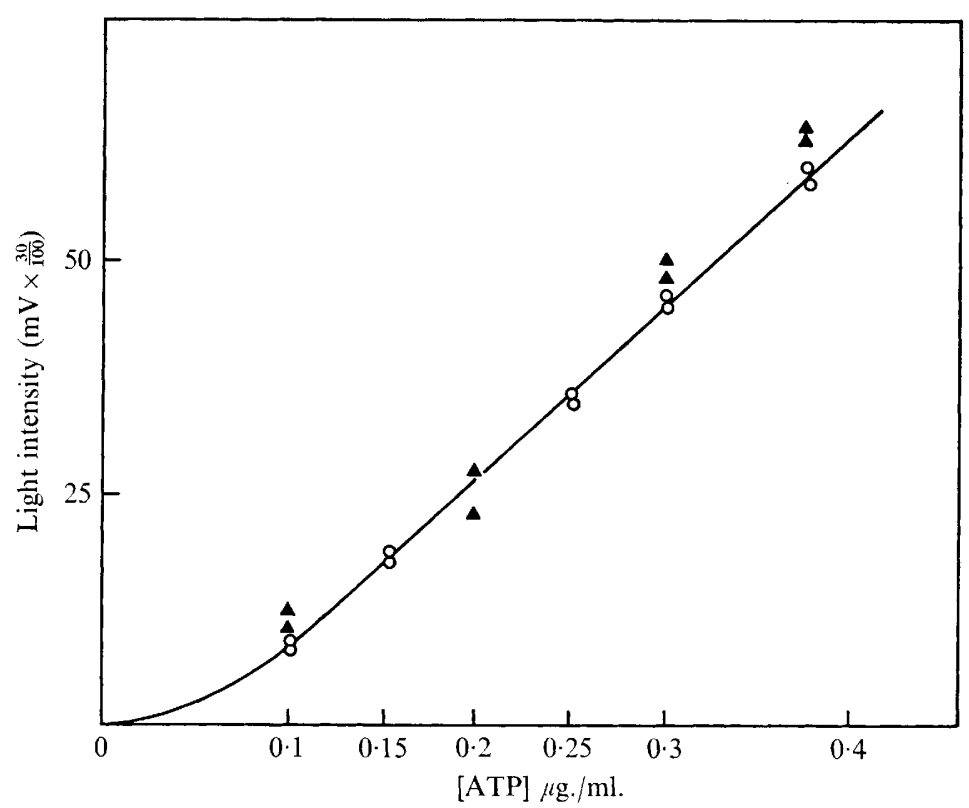

Fig. 2. Influence of ADP on the ATP determination. $O$, Measurement done with pure ATP; $\Delta$, measurement with a mixture of equal quantities of ATP and ADP.

by the method of Lowry, Rosebrough, Farr \& Randall (195I). The cellular extract was obtained from a culture of $20 \mathrm{I}$ harvested after $\mathrm{I} 2 \mathrm{~h}$ of incubation, after which the organisms were broken by a Raytheon ultrasonicator.

\section{RESULTS}

Determination of the ATP pool variation under optimal coupling growth conditions of culture limited by the energy source

Figure 3 shows the cellular ATP pool in the exponential growth phase on the three different culture media (complex, defined and minimal). For all media, the ATP pool was constant during the log phase. The mean values for the ATP pool were very similar for the complex and defined media. It was about twice as high when the organism was grown on minimal medium (Table I).

When growth was limited by glucose, the ATP level was completely depressed at the beginning of the stationary phase and reached a value of $0.4 \mu \mathrm{g} \mathrm{ATP} / \mathrm{mg}$ dry wt (Fig. 4). The fall in the ATP pool occurred about $2.5 \mathrm{~h}$ before the beginning of the stationary phase. This time corresponds to about a generation time under these growth conditions.

Figure 5 shows the formation of the ATP pool at the beginning of growth on a complex medium. For this purpose, the organism was grown on this medium and glucose added $3 \mathrm{~h}$ after growth had ceased. This time was set as the time zero of the experiment. This procedure avoided the stressing treatment of the inoculation and permitted the establishment of a direct relation between the stationary and the log phase. No lysis occurred during io $\mathrm{h}$ following the beginning of the stationary phase of growth. The ATP pool, which was very small $(0.4 \mu \mathrm{g} / \mathrm{mg}$ dry $\mathrm{wt})$ at the beginning of the log phase, passed through a maximum $(2.5 \mu \mathrm{g} / \mathrm{mg}$ dry wt) and became constant $2 \mathrm{~h}$ after the zero time of the experiment. This 

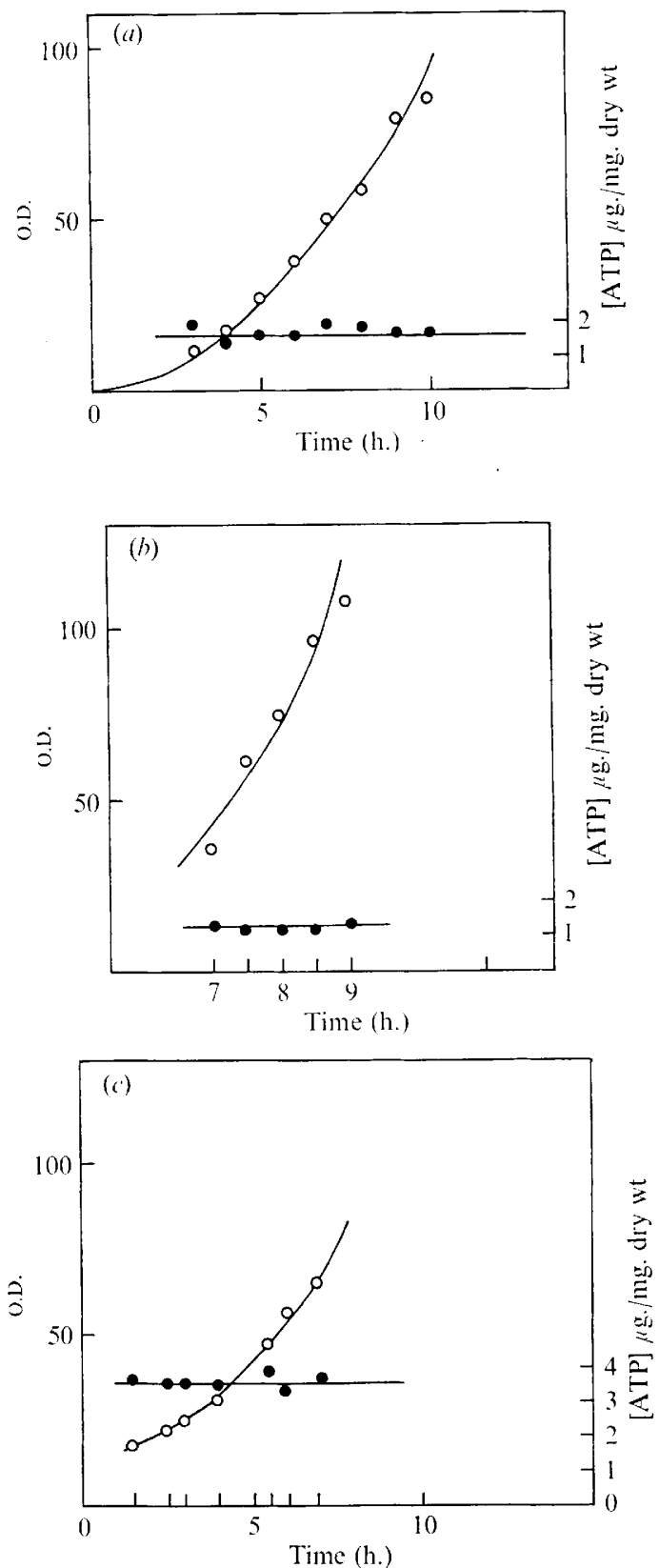

Fig. 3.A TP pool evolution during log phases of growth: $(a)$ on defined medium; $(b)$ on complex medium; (c) on minimal medium. O, o.D. at $475 \mathrm{~nm}$ (o.D.: in arbitrary units); $\bullet$, [ATP] $\mu \mathrm{g} / \mathrm{mg}$ dry wt. 


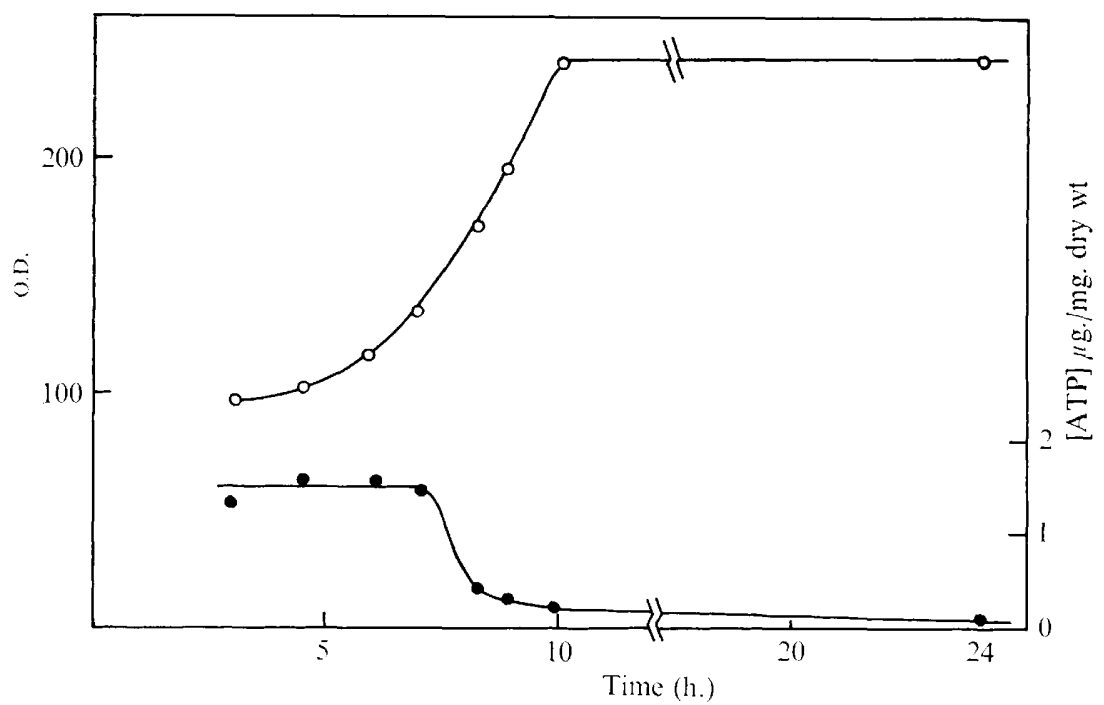

Fig. 4. ATP pool evolution at the end of a glucose-limited growth. O, o.D. at $475 \mathrm{~nm}$ (o.D.: in arbitrary units); $\mathbf{0}$ [ATP] $\mu \mathrm{g} / \mathrm{mg}$ dry wt.

demonstrates that the steady state was not immediately reached as it was in the shift-up for glucose, previously described.

\section{Determination of the ATP pool in pantothenate-starved growth}

Figure 6 shows the development of the ATP pool during the log phase, in uncoupling conditions of growth, in synthetic and minimal media poor in pantothenate. For the defined medium, the initial concentration of pantothenate was $10^{-7} \mathrm{mg} / \mathrm{ml}$ and the uncoupling thus engendered corresponded to a specific growth rate and a molecular growth yield respectively of $0 \cdot 20 \mathrm{I}^{-1}$ and $2 \cdot 8$. Under these conditions the ATP concentration was twofold higher than was the corresponding value obtained under coupling conditions of growth

Table I. Growth parameters and ATP pool of Zymomonas mobilis in different growth conditions

\begin{tabular}{|c|c|c|c|c|c|}
\hline $\begin{array}{l}\text { Culture } \\
\text { conditions }\end{array}$ & $\begin{array}{c}\text { Pantothenate } \\
\text { concentrations } \\
(\mathrm{mg} / \mathrm{ml})\end{array}$ & $\begin{array}{l}\text { Molar } \\
\text { growth yield } \\
\text { on glucose } \\
\left(Y_{\mathrm{g}}\right)\end{array}$ & $\begin{array}{c}\text { Specific } \\
\text { growth rate } \\
\left(\mu \mathrm{h}^{-1}\right)\end{array}$ & $\begin{array}{l}\text { Cellular rate } \\
\text { of catabolic } \\
\text { activity } \\
\left(\mathrm{mmole}^{-1}\right. \\
\left.\min ^{-1} \mathrm{~g}^{-1}\right)\end{array}$ & $\begin{array}{c}\text { ATP pool } \\
(\mu \mathrm{g} / \mathrm{mg} \text { dry wt }) \\
\text { means with a } \\
\text { confidence value } \\
\text { equal } 99 \%\end{array}$ \\
\hline $\begin{array}{l}\text { Complex medium } \\
\text { (tris buffer) }\end{array}$ & 一 & 7 & 0.37 & 0.90 & $I \cdot 54 \pm 0.15$ \\
\hline Defined medium & $5 \times 10^{-3}$ & $6 \cdot 4$ & $0 \cdot 39$ & $\mathrm{I} \cdot 02$ & $1.55 \pm 0.22$ \\
\hline Minimal medium & $5 \times 10^{-3}$ & $4 \cdot 5$ & 0.28 & $\mathrm{I} \cdot 07$ & $3.55 \pm 0.18$ \\
\hline $\begin{array}{l}\text { Defined medium } \\
\text { with limiting } \\
\text { pantothenate } \\
\text { concentration }\end{array}$ & $10^{-7}$ & $2 \cdot 8$ & 0.20 & $I \cdot 12$ & $3.15 \pm 0.40$ \\
\hline $\begin{array}{l}\text { Minimal medium } \\
\text { with limiting } \\
\text { pantothenate } \\
\text { concentration }\end{array}$ & $10^{-6}$ & $2 \cdot 9$ & $0 \cdot 16$ & 0.95 & $4.52 \pm 0.21$ \\
\hline I3 & & & & & MIC 70 \\
\hline
\end{tabular}




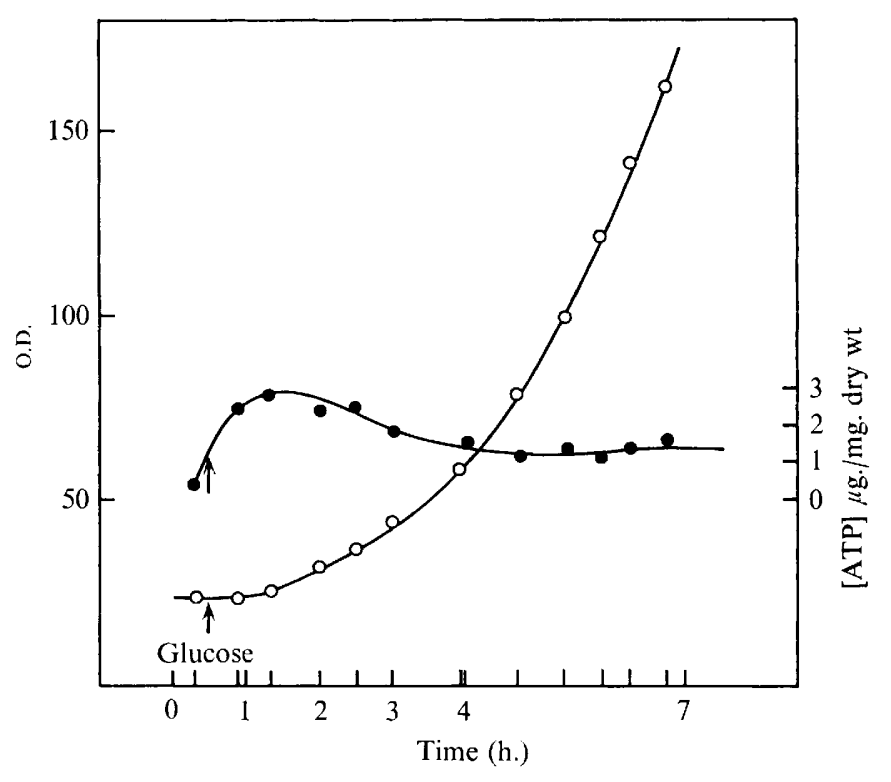

Fig. 5. ATP pool evolution at the beginning of a glucose-limited growth. O, O.D. at $475 \mathrm{~nm}$ (O.D.: in arbitrary units); 9 , [ATP] $\mu \mathrm{g} / \mathrm{mg}$ dry wt.

(Table I). For the minimal medium, similar results were obtained. In the log phase, the ATP pool was also higher than it was under corresponding coupling conditions (Table I).

\section{Determination of the ATP pool under the conditions where growth was blocked by nitrogen starvation and by chloramphenicol inhibition}

When uncoupling was caused by low pantothenate concentrations (as above), growth was still exponential (Belaich et al. I97I). We have also been interested in the ATP pool variation under conditions where the synthesis was stopped at once. For this purpose, we have measured the ATP pool when the growth was stopped by chloramphenicol and by nitrogen starvation.

After the injection of chloramphenicol, at a final concentration of $50 \mu \mathrm{g} / \mathrm{ml}$, the optical density in both complex and minimal media remained constant. The ATP pool increased immediately from $\mathrm{I} \cdot 5$ to $3 \mu \mathrm{g} / \mathrm{mg}$ dry wt in complex medium and from 3.5 to $4.8 \mu \mathrm{g} / \mathrm{mg}$ dry wt in minimal medium (Fig. 7).

Chloramphenicol did not affect the cellular rate of catabolic activity (Fig. 8). This thermogram obtained by the microcalorimetric technique shows that the heat flux, which is proportional to the catabolic activity of the culture (Belaich \& Senez, I965), remained constant after addition of chloramphenicol.

When the growth was stopped by nitrogen starvation, the change in ATP concentration was different from that previously described. The ATP pool remained constant during the $\log$ phase, and decreased just $3 \mathrm{~h}$ before the complete cessation of nitrogen-starved growth (Fig. 9); a result similar to that with glucose-limited growth. However, the final ATP pool was threefold higher than it was for glucose-limited growth. The nitrogen starvation involved a decrease of the cellular rate of catabolic activity (Fig. I0; also Belaich, I967); the heat 

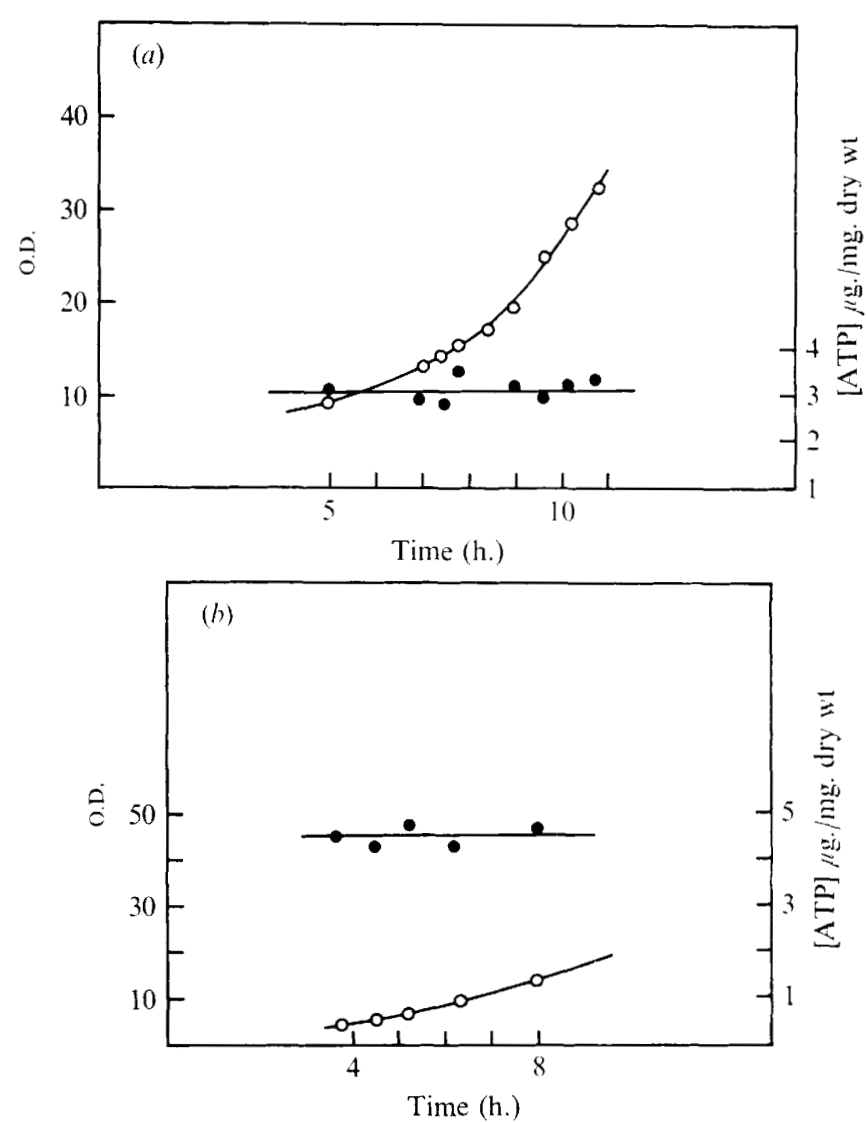

Fig. 6. ATP pool evolution during log phases of uncoupled pantothenate-starved growth: $(a)$ on defined medium [pantothenate] $=\mathrm{IO}^{-7} \mathrm{mg} / \mathrm{ml} ;(b)$ on minimal medium [pantothenate] $=10^{-6}$ $\mathrm{mg} / \mathrm{ml}$. O. O.D. at $475 \mathrm{~nm}$ (O.D.: in arbitrary units); $\bullet$, [ATP] $\mu \mathrm{g} / \mathrm{mg}$ dry wt.

flux dropped to above $50 \%$ after exhaustion of the nitrogen $\left(\mathrm{NH}_{4}{ }^{+}\right)$content of the minimal medium. In other words, cessation of growth by nitrogen starvation led to a simultaneous decrease of the cellular rate of the catabolic activity and of the ATP pool.

\section{DISCUSSION}

In both coupling and uncoupling conditions of the log phase, the ATP pool was constant. Although this observation is in good agreement with the concept of the steady state of cells during the log phase, it does not agree with the results of many authors. Indeed, Forrest (I965) has reported that the ATP pool of Streptococcus faecalis decreased during the $\log$ phase. Also, Cole et al. (1967) found that the ATP pool in Escherichia coli was constant during the log phase of growth only on rich media. It appears from their experiments that one may observe under- or over-production of ATP during the log phase. In our experiments, we have measured both the cellular rate of catabolic activity and the ATP pool: for Zymomonas mobilis, these two parameters were constant during the log phase of growth for any type of medium utilized and for any energetic coupling condition of growth, as 

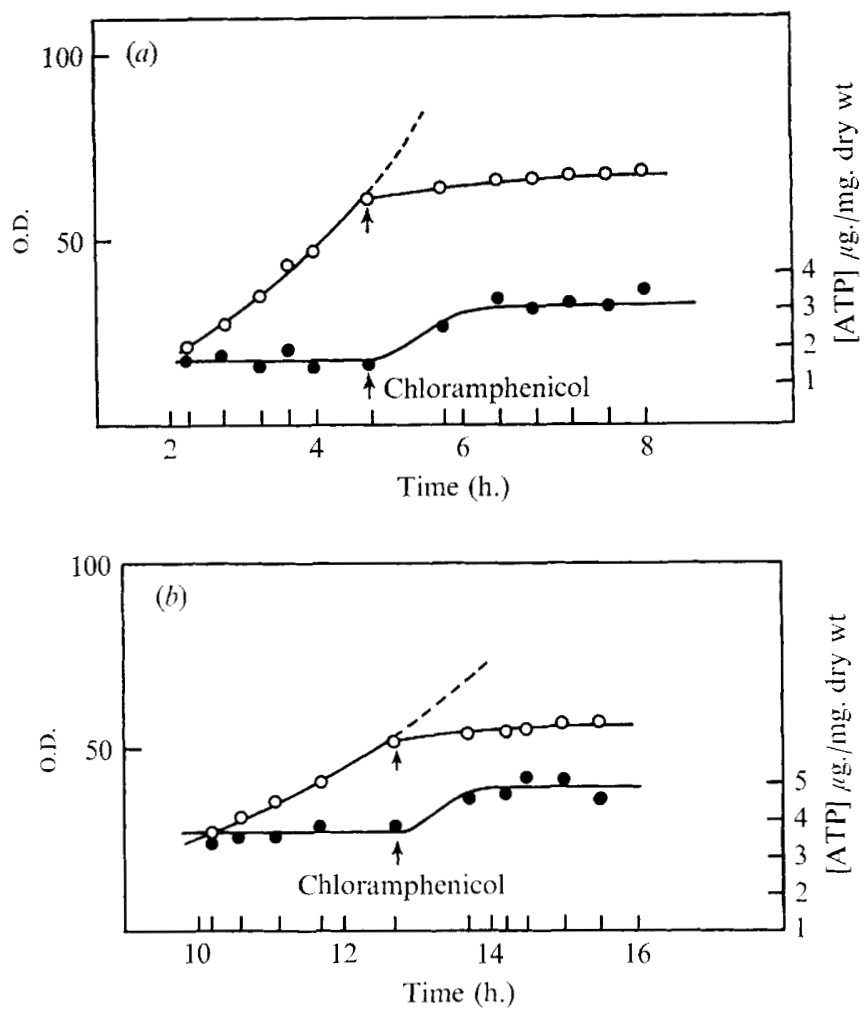

Fig. 7. Influence of chloramphenicol on growth and on ATP pool: $(a)$ on complex medium; (b), on minimal medium. O, o.D. at $475 \mathrm{~nm}$ (o.D.: in arbitrary units);, , [ATP] $\mu \mathrm{g} / \mathrm{mg}$ dry wt.

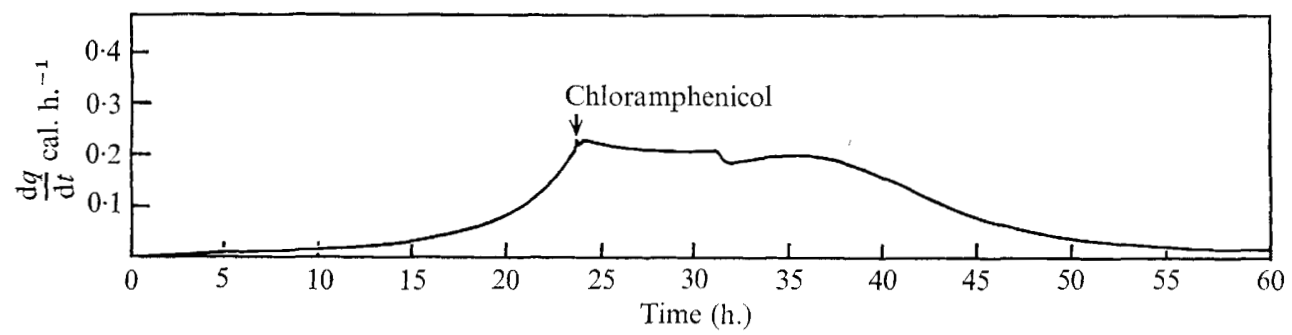

Fig. 8. Thermogram of growth blocked by chloramphenicol. (Chloramphenicol was added during exponential growth $\downarrow$.)

defined previously (Belaich et al. 1972). In other words, for Z. mobilis, energy production and energy consumption are always well balanced in the log phase of growth.

Although the ATP pool was constant in the log phase, the value reached was dependent on the culture medium and also on the coupling conditions of growth. Figure I I and Table I show that the ATP pool was the same in the complex and in the defined media, and was half that in minimal medium. Moreover, the ATP pool was much higher in uncoupling by pantothenate starvation than it was in corresponding control experiments. These data could support the general concept of over- and under-production of ATP put forward by Cole et al. (1967). However, our experiments suggest an under-consumption of ATP. 


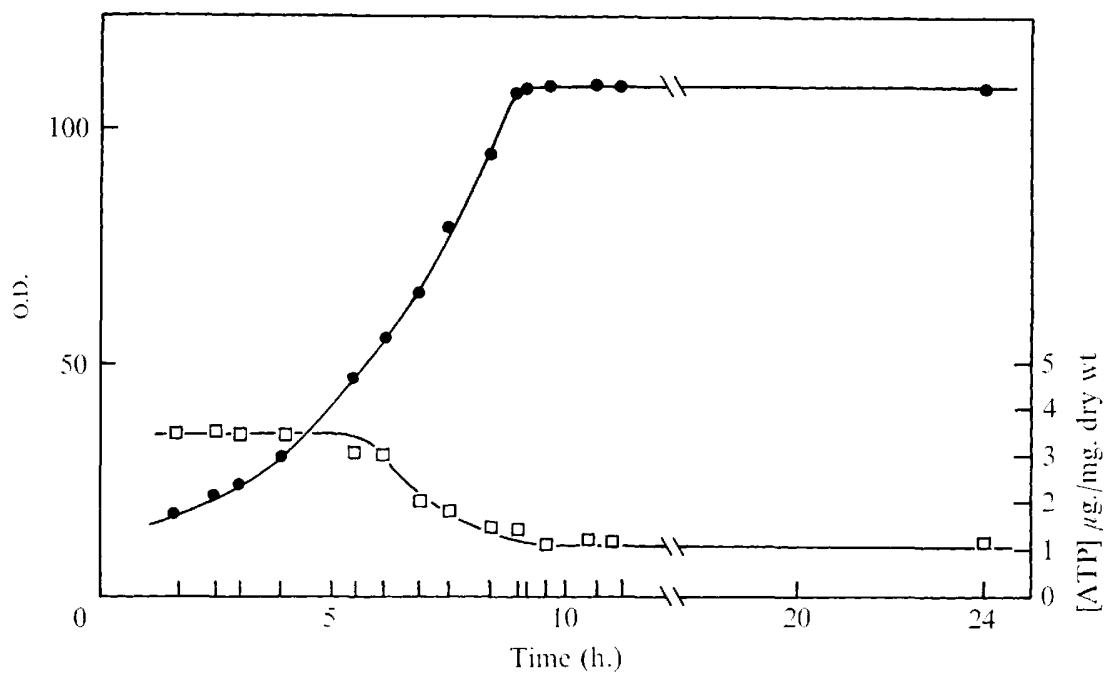

Fig. 9. Influence of nitrogen starvation on the ATP pool. O, O.D. at $475 \mathrm{~nm}$ (O.D.: in arbitrary units); $\square$, (ATP) $\mu \mathrm{g} / \mathrm{mg}$ dry wt.

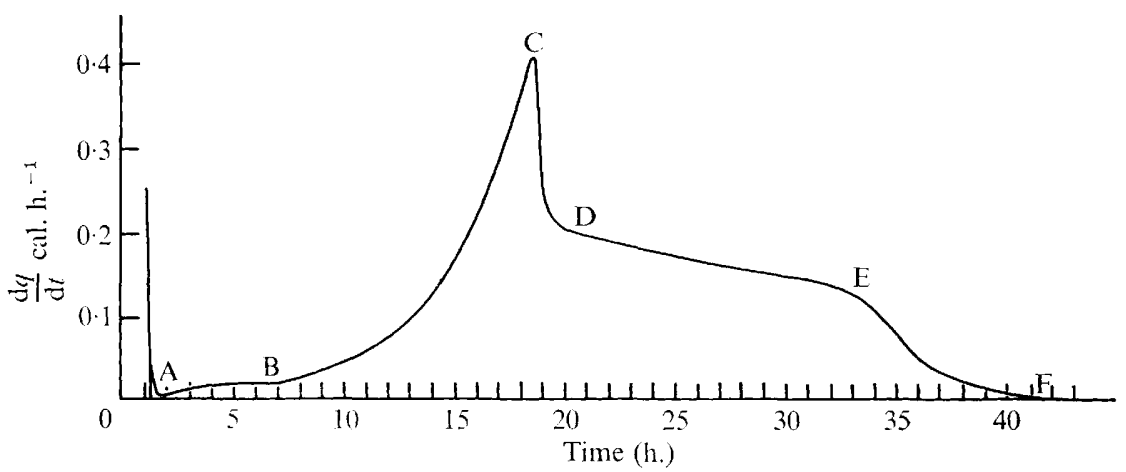

Fig. Io. Thermogram of nitrogen-starved growth (after Belaich \& Senez, 1965 b). ABC: logarithmic growth phase. At point $\mathrm{C}, \mathrm{NH}^{4}+$ becomes limiting. $\mathrm{CDE}$ : kinetics of glucose degradation without growth. At point $\mathrm{F}$ glucose is depleted.

Indeed, as can be seen in Fig. 12, the ATP pool was inversely proportional to the specific growth rate, whereas the cellular rate of catabolic activity remained constant in the range of specific growth examined. In other words, the ATP pool was as high as the demand for ATP in biosynthesis was low.

The fact that the energy production and consumption were always well balanced raises the question of the dissipation of the energy produced in the uncoupling growth conditions. One can postulate the existence in the cells of a mechanism by which excess ATP could be eliminated via a direct or indirect ATPase, as discussed previously (Belaich et al. 1972). The rate of ATP hydrolysis will be equal to the difference between its production by catabolic processes and its utilization by anabolic processes. Some preliminary experiments concerning a direct ATPase activity have been done, the results of which are reported in the Table 2. The same ATPase activity has been observed both in coupling and uncoupling growth conditions; this ATPase seemed to be associated with membrane and specific for nucleotide triphosphates. The $K_{m}$ determined for ATP was $10^{-3} \mathrm{M}$. The presence of this constitutive 


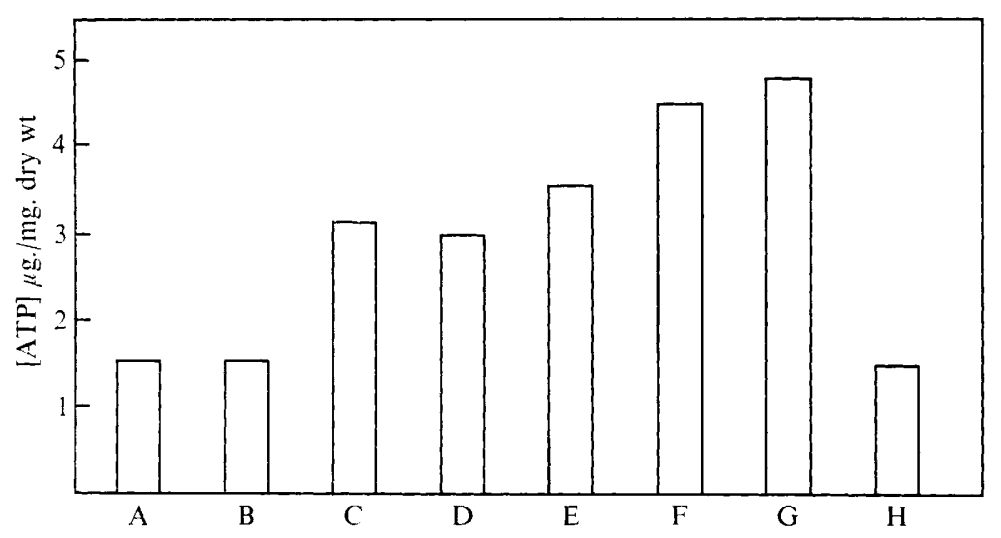

Fig. I I. Comparison of ATP pool in the different physiological conditions studied. A, On complex medium; B, on synthetic medium; $\mathbf{C}$, on synthetic medium with limiting pantothenate concentration; D, on synthetic medium after addition of chloramphenicol; $\mathrm{E}$, on minimal medium; $\mathrm{F}$, on minimal medium with limiting pantothenate concentration; $G$, on minimal medium after addition of chloramphenicol; $\mathrm{H}$, on minimal medium after nitrogen starvation.

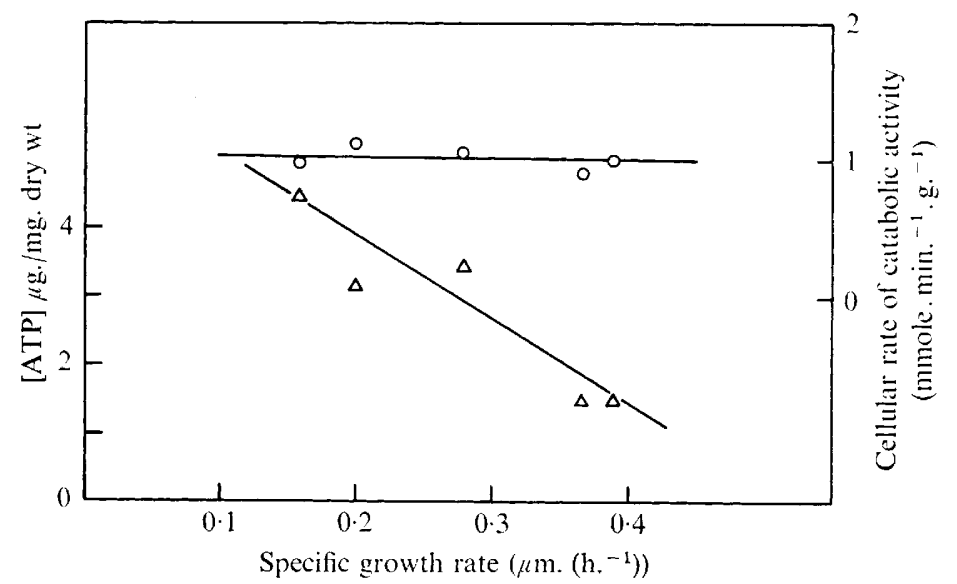

Fig. 12. ATP pool $(\triangle-\triangle)$ and cellular rate of catabolic activity $(\mathrm{O}-\mathrm{O})$ versus specific growth rate.

Table 2. Characteristics of ATPase activity in extracts of Zymomonas mobilis

ATPase activity ( $\mu$ mole of Pi min $^{-1} \mathrm{mg}^{-1}$ protein)

Constitutivity

Localization

Substrate specificity

$K_{m}$ for ATP $=10^{-3} \mathrm{M}$

\section{Coupling growth} Uncoupling growth

Supernatant Insoluble

ATP

GTP

ADP

AMP
0.18

0.17

0.14

0.45

0.15

$0.1 \mathrm{I}$

0.04

0.002 
ATPase having a low affinity for ATP in Zymomonas mobilis could have been responsible for the elimination of the excess ATP which appeared in high concentrations in the uncoupling conditions.

As with pantothenate starvation so also the blockage of protein synthesis by chloramphenicol involved an increase of the ATP pool without a decrease of the cellular catabolic activity. Surprisingly, the physiological effects of nitrogen starvation seem in opposition to the results of experiments carried out with chloramphenicol and pantothenate. Nitrogen starvation involved a diminution of the cellular rate of catabolic activity and of the value of the ATP pool (Fig. 9, I0). This contradiction is only apparent and can be easily explained. Although in both cases the synthetic processes were blocked, with chloramphenicol all the monomers of the synthesis were in excess whereas nitrogen starvation involved a diminution of all the metabolites, especially of the nucleotide pool. This could have been responsible for the control of the catabolic activity observed during nitrogen starvation.

\section{REFERENCES}

ATKinson, D. E. (1968). The energy charge of the adenylate pool as a regulatory parameter. Interaction with feedback modifiers. Biochemistry 7, 4030-4034.

AtKinson, D. E. \& Fall, L. (1967). Adenosine triphosphate conservation in biosynthetic regulation. E. coli phosphoribosyl pyrophosphate synthase. Journal of Biological Chemistry 242, 324I-3242.

Atkinson, D. E. \& Walton, G. M. (1967). Adenosine triphosphate conservation in metabolic regulation. Rat liver citrate cleavage enzyme. Journal of Biological Chemistry 242, 3239-324I.

Belaich, J. P., Belaich, A. \& Simonpietri, P. (1972). Uncoupling in bacterial growth: Effect of pantothenate starvation on growth of Zymomonas mobilis. Journal of General Microbiology 70, 179-185.

BeLaich, J. P. \& Senez, J. C. (I965a). Influence of aeration and of pantothenate on growth yields of Zymomonas mobilis. Journal of Bacteriology 89, I I $95-1200$.

Belaich, J.P. \& Senez, J.C. (I965b). Application de la méthode microcalorimétrique à l'étude de l'énergétique de la croissance bactérienne. Colloque International du Centre National de la Recherche Scientifique 156, 38I-394.

Cole, H. A., Wimpenny, J. W. T. \& Hughes, D. E. (1967). The ATP pool in Escherichia coli. I. Measurement of the pool using a modified luciferase assay. Biochimica et biophysica acta I43, 445-453.

Cousin, D. \& Belaich, J. P. (I966). Sur une mutation thermosensible d'Escherichia coli affectant une fonction énergétique. Comptes rendus de l'Académie des sciences 263, 886-888.

Damoglou, A. P. \& Dawes, E. A. (1967). Studies on the lipid content and phosphate requirement of glucose- and acetate-grown Escherichia coli. Biochemical Journal ro2, 37p.

FisKE, C. H. \& SubBarow, V. (1925). The colorimetric determination of phosphorus. Journal of Biological Chemistry 66, 375-400.

ForRest, W. W. (I965). Adenosine triphosphate pool during the growth cycle in Streptococcus faecalis. Journal of Bacteriology 9o, I0I3-IOI8.

ForRest, W. W. \& WALKeR, D. J. (1965). Synthesis of reserve materials for endogenous metabolism in Streptococcus faecalis. Journal of Bacteriology 89, I448-1452.

Franzen, J. S. \& BinkLeY, S. B. (I96I). Comparison of the acid-soluble nucleotides in Escherichia coli at different growth rates. Journal of Biological Chemistry 236, 5I 5-519.

Kelly, D. P. \& SYRETT, P. J. (I966). Energy coupling during sulphur compound oxidation by Thiobacillus. Journal of General Microbiology 43, I09-1 I8.

Kiflley, W. W. (1955). Mitochondrial ATPase. In Methods in Enzymology, vol. 2, pp. 593-595. Edited by S. P. Colowick \& N. O. Kaplan. London and New York: Academic Press.

Lowry, O. H., Rosebrough, N. J., Farr, A. L. \& Randall, R. J. (I95I). Protein measurement with the folin phenol reagent. Journal of Biological Chemistry 193, 265-275.

POLAKIS, E. S. \& BARTLEY, W. (I966). Changes in intracellular concentrations of adenosine phosphates and nicotinamide nucleotides during aerobic growth of yeast. Biochemical Journal 99, 52 I-533.

Strange, R. E., Wade, H. E. \& Dark, F. A. (1963). Effect of starvation on adenosine triphosphate concentration in Aerobacter aerogenes. Nature, London 199, 55-57.

Strehler, B. L. \& TotTer, J. R. (I952). Firefly luminescence in the study of energy transfer mechanisms. Archives of Biochemistry and Biophysics 40, 28-4I. 